\title{
Enhanced selectivity in the conversion of methanol to 2,2,3-trimethylbutane (triptane) over zinc iodide by added phosphorous or hypophosphorous acid $\dagger$
}

\author{
John E. Bercaw, Robert H. Grubbs, Nilay Hazari, Jay A. Labinger* and Xingwei Lił \\ Received (in Cambridge, UK) 11th April 2007, Accepted 6th June 2007 \\ First published as an Advance Article on the web 20th June 2007 \\ DOI: 10.1039/b705470j
}

The yield of triptane from the reaction of methanol with zinc iodide is dramatically increased by addition of phosphorous or hypophosphorous acid, via transfer of hydride from a $\mathbf{P}-\mathbf{H}$ bond to carbocationic intermediates.

Methanol is expected to play an increasingly important role as an energy source and chemical intermediate. One approach that has attracted recent attention is the dehydrative conversion of methanol to hydrocarbons; ${ }^{1}$ in particular, conversion of methanol to light olefins (MTO) over zeolitic materials has been the object of intense mechanistic study. ${ }^{2}$ In contrast, the reaction of methanol over zinc iodide gives a highly-branched $\mathrm{C}_{7}$ alkane, 2,2,3trimethylbutane (triptane, Eq. 1), in surprisingly high selectivity (up to $20 \%$ yield on a moles carbon basis). ${ }^{3}$ We recently reported extensive studies implicating a carbocation-based mechanism for this transformation, involving successive methylation of lighter olefinic intermediates and hydride transfer to the resulting carbocations to generate alkanes, along with multiply unsaturated species that end up mainly as methylated benzenes. ${ }^{4}$ We report here that the yield is significantly enhanced by the addition of certain phosphorus reagents, whose unusual mode of operation is consistent with the previously proposed mechanistic explanation of selectivity.

$$
\mathrm{CH}_{3} \mathrm{OH} \stackrel{\mathrm{Znl}_{2}}{200^{\circ} \mathrm{C}} \stackrel{\text { triptane }}{\longrightarrow}<\text { (inter alia) }+\mathrm{H}_{2} \mathrm{O}
$$

As part of our ongoing research program on this system, we examined the effect of water-sequestering agents, since water (produced at the earliest stages of reaction by dehydration of methanol to dimethyl ether) was observed to inhibit conversion. Several such additives, including trimethyl orthoformate, dimethyl carbonate, $\mathrm{P}_{2} \mathrm{O}_{5}$, and trimethyl phosphate had little or no effect. In contrast, addition of trimethyl phosphite $(7 \mathrm{~mol} \%$ relative to methanol) resulted in a marked increase in yield, from $18 \%$ to $24 \%$, even after accounting for the additional carbon provided in the additive (Table 1).

We can conceive of at least four mechanisms (besides water removal, which does not appear to have a beneficial effect) by

Arnold and Mabel Beckman Laboratories of Chemical Synthesis, California Institute of Technology, Pasadena, California, USA 91125.

E-mail: jal@its.caltech.edu; Fax: 1-626-449-4159; Tel: 1-626-395-6520

$\uparrow$ Electronic supplementary information (ESI) available: Experimental details, additional tabular results, ${ }^{31} \mathrm{P}$ NMR spectra, and discussion of mechanistic alternatives. See DOI: 10.1039/b705470j

* Present address: Division of Chemistry and Biological Chemistry, Nanyang Technological University, Singapore, 639623. which trimethyl phosphite could modify the chemistry: 1) by increasing the acidity of the medium; 2) as a ligand for $\mathrm{Zn}^{2+}$, changing the nature of the catalyst; 3) as a more efficient methylating agent, in an Arbuzov-like reaction; and 4) as a reducing agent. The absence of a similar effect for trimethyl phosphate appears to rule out the first. ${ }^{31} \mathrm{P}$ NMR spectroscopy demonstrates that the water liberated by dimethyl ether formation rapidly hydrolyzes trimethyl phosphite to a mixture of phosphorous acid and its monomethyl ester. Both of these exist almost entirely as the phosphoryl tautomer ${ }^{5}$ and hence would not be available for either the second or third function, suggesting the reducing agent explanation is the most likely. Indeed, at the end of the reaction the only significant ${ }^{31} \mathrm{P}$ NMR signal is that of $\mathrm{H}_{3} \mathrm{PO}_{4}$.

According to this interpretation, phosphorous acid should work just as well as trimethyl phosphite, while hypophosphorous acid, which has two $\mathrm{P}-\mathrm{H}$ bonds, should be equally good or even better. Indeed, as shown in Table 1, the results using $\mathrm{H}_{3} \mathrm{PO}_{3}$ and $\mathrm{P}(\mathrm{OMe})_{3}$ are identical (after correcting for the additional methyl groups provided by the latter), while $\mathrm{H}_{3} \mathrm{PO}_{2}$ gives additional enhancement, up to $32 \%$ yield. The highest yield (36\%, nearly double the baseline case) was obtained with $\mathrm{H}_{3} \mathrm{PO}_{2}$ by reducing the reaction temperature (at the cost of a much longer reaction time). ${ }^{31} \mathrm{P}$ NMR spectra (Fig. 1), followed over the course of the latter reaction, shows that $\mathrm{H}_{3} \mathrm{PO}_{2}$ is indeed oxidized, first to $\mathrm{H}_{3} \mathrm{PO}_{3}$ and ultimately to $\mathrm{H}_{3} \mathrm{PO}_{4}$.

Table 1 Triptyl $^{a}$ yields from the reaction of methanol and zinc iodide in the absence and presence of $\mathrm{P}-\mathrm{H}$ bonded additives ${ }^{b}$

\begin{tabular}{lcll}
\hline $\begin{array}{l}\text { Additive, mol } \% \\
\text { (rel. to MeOH) }\end{array}$ & $\begin{array}{l}\text { Triptyl } \\
\text { yield, } \\
\text { mg }\end{array}$ & $\begin{array}{l}\text { Triptyl yield, } \\
\% \text { based on } \\
\text { MeOH }\end{array}$ & $\begin{array}{l}\text { Triptyl yield, } \\
\% \text { based on } \\
\text { total C }\end{array}$ \\
\hline- & 66 & 19 & 18 \\
$\mathrm{PO}(\mathrm{OMe})_{3}, 6.8 \%$ & 69 & 20 & 16 \\
$\mathrm{P}(\mathrm{OMe})_{3}, 6.8 \%$ & 108 & 31 & 24 \\
$\mathrm{P}(\mathrm{OMe})_{3}, 1.7 \%{ }^{c}$ & 65 & 18 & 17 \\
$\mathrm{P}(\mathrm{OMe})_{3}, 3 . \%^{c}$ & 100 & 28 & 23 \\
$\mathrm{P}(\mathrm{OMe})_{3}, 10 . \%^{c}$ & 102 & 29 & 21 \\
$\mathrm{H}_{3} \mathrm{PO}_{3}, 6.8 \%$ & 89 & 25 & 23 \\
$\mathrm{H}_{3} \mathrm{PO}_{2}, 7.4 \%$ & 122 & 35 & 32 \\
$\mathrm{H}_{3} \mathrm{PO}_{2}, 7 . \%^{c}$ & 129 & 36 & 36
\end{tabular}

${ }^{a}$ Yields are given as total "triptyls", triptane plus triptene, as these are not cleanly separated by our routine GC analytical procedure. The relative amounts can be readily distinguished by ${ }^{13} \mathrm{C}$ NMR spectroscopy. ${ }^{b}$ Except as noted, reactions were carried out as previously described ${ }^{4}$ for $3 \mathrm{~h}$ at $200{ }^{\circ} \mathrm{C}$, using $790 \mathrm{mg} \mathrm{MeOH}$ with $32 \mathrm{~mol}^{\%} \mathrm{ZnI}_{2}$ as catalyst, $2.6 \mathrm{~mol} \% i$ - $\mathrm{PrOH}$ as promoter, and the indicated $\mathrm{mol} \%$ of additive. ${ }^{c}$ Reaction time $2 \mathrm{~h} .{ }^{d}$ Reaction carried out at $175^{\circ} \mathrm{C}$ for $24 \mathrm{~h}$; no $i$-PrOH added. 


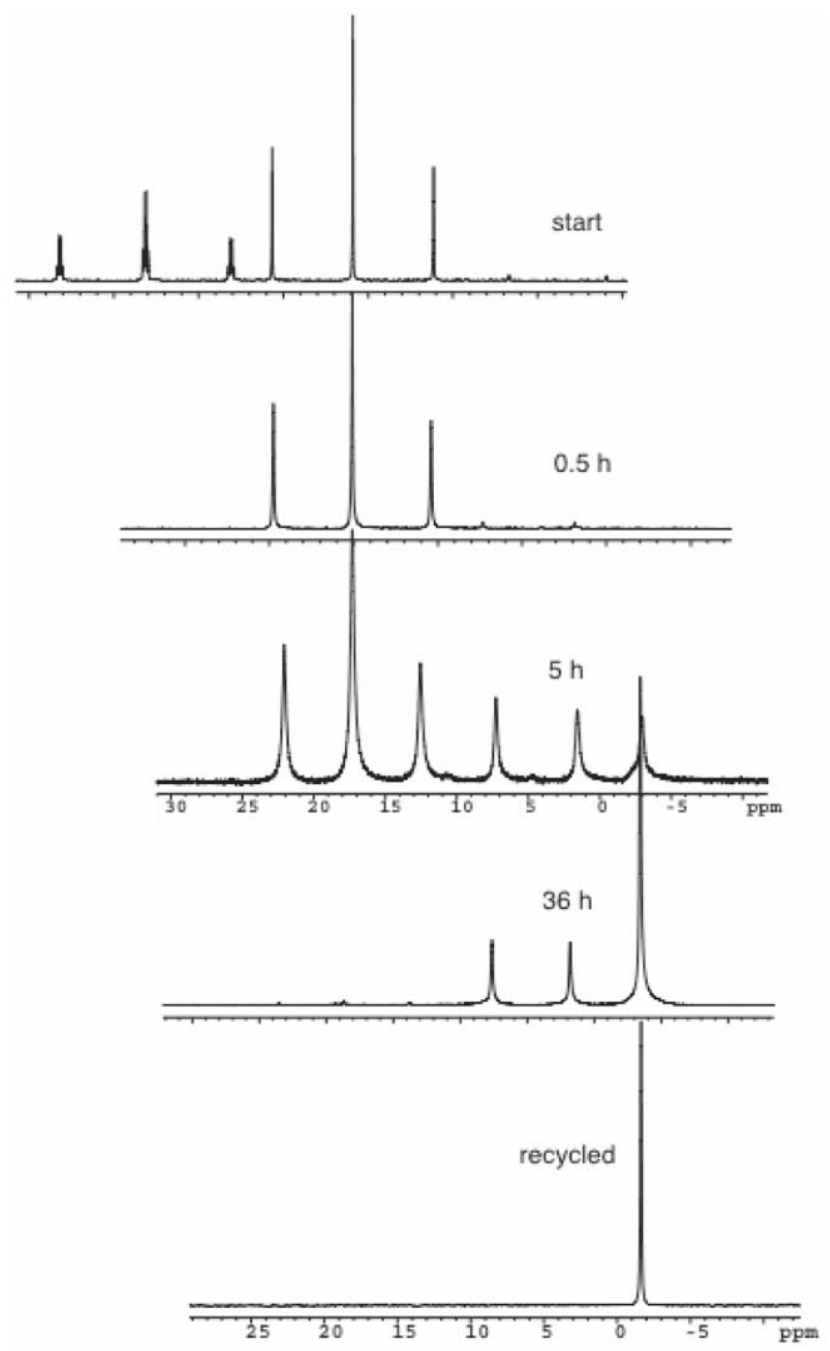

Fig. 1 Evolution of ${ }^{31} \mathrm{P}$ spectrum of $\mathrm{H}_{3} \mathrm{PO}_{2}-\mathrm{ZnI}_{2}-\mathrm{MeOH}$ heated at $170{ }^{\circ} \mathrm{C}$ for indicated times. The initial mixture of $\mathrm{H}_{2} \mathrm{PO}(\mathrm{OH})$ and $\mathrm{H}_{2} \mathrm{PO}(\mathrm{OMe})$ (the latter rapidly hydrolyzes) gradually converts to $\mathrm{HPO}(\mathrm{OH})_{2}$ and then $\mathrm{PO}(\mathrm{OH})_{3}$. The last spectrum was obtained by adding a fresh charge of $\mathrm{MeOH}$ and repeating the reaction.

Why should a reducing agent enhance the yield? Although the stoichiometric products of methanol dehydration (equivalent to $\mathrm{CH}_{2}+\mathrm{H}_{2} \mathrm{O}$ ) would be alkenes, most of the triptyls (and lighter species as well) are found as alkanes; for example, in a typical reaction (without any phosphorus additive) the ratio of triptane : triptene is around $8: 1$. We believe that the additional hydrogen required is obtained by dehydrogenation of some of the hydrocarbons produced during condensation, via a mechanism such as that illustrated (for one particular combination of many possible) in Eq. 2. Subsequent transformations of the multiunsaturated intermediates result ultimately in arenes, of which hexamethylbenzene (HMB) is by far the largest component. ${ }^{4}$ The $\mathrm{P}-\mathrm{H}$ bond-containing reagents serve as an alternate source for some of the hydrogen, thus reducing the fraction of hydrocarbon that must be diverted from the triptane-producing sequence into the arene pool.

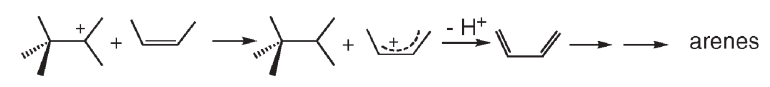

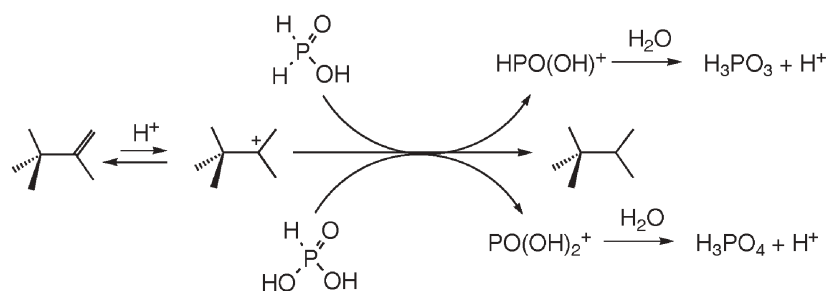

Scheme 1

In agreement with this model, we find that these additives effect significant changes (besides the yield increase) to the product distribution: the yields of both aromatics (including HMB) and olefins are substantially reduced. $\uparrow$ In particular, the triptyl fraction is nearly all triptane. In a separate experiment, triptene was found to be quantitatively reduced to triptane on heating with a slight excess of $\mathrm{H}_{3} \mathrm{PO}_{2}$ in a methanolic solution of $\mathrm{ZnI}_{2}$ at $170{ }^{\circ} \mathrm{C}$ for $3 \mathrm{~h}$.

The most common reaction of $\mathrm{P}-\mathrm{H}$ bond-containing species with olefins is addition, via a radical-chain mechanism; ${ }^{6}$ indeed, when triptene is heated as above with $\mathrm{H}_{3} \mathrm{PO}_{2}$ but no $\mathrm{ZnI}_{2}$, no triptane is formed, and the ${ }^{31} \mathrm{P}$ NMR spectrum shows a small signal consistent with formation of the addition product. In contrast, a combination of $\mathrm{H}_{3} \mathrm{PO}_{2}$ and $p$-toluenesulfonic acid effects partial hydrogenation of triptene or 2,3-dimethylbut-2-ene, but not hex-1-ene. This observation suggests that reduction by $\mathrm{P}-\mathrm{H}$ proceeds via the mechanism of Scheme 1 , for which a relatively stable carbocationic intermediate is required.

Ionic hydrogenation with $\mathrm{P}-\mathrm{H}$ acting as hydride donor is rare ll (although there is at least one precedent ${ }^{8}$ ). We have not found any similar yield enhancements with alternate reducing agents; in particular, potential hydride donors such as $(\mathrm{MeO})_{3} \mathrm{SiH}$ are rapidly destroyed (evolution of $\mathrm{H}_{2}$ is observed). It appears that a delicate balance is required for this mode of yield enhancement: a reagent must be sufficiently hydridic to capture carbocationic intermediates fast enough to inhibit the arene-producing reactions of Eq. 2, but not so much so that it is unstable to the acidic reaction conditions. Whether this behavior is unique to the $\mathrm{P}-\mathrm{H}$ compounds studied here, and whether it may be applicable to modifying reactivity in other systems that involve carbocationic intermediates, remains to be established.

We thank Glenn Sunley and Patrick Vagner for useful discussions, and Eugene Zaluzec for obtaining the PIANO analysis. This work was supported by $\mathrm{BP}$ through the $\mathrm{MC}^{2}$ program.

\section{Notes and references}

$\S$ Addition of small amounts of acids (such as $p$-toluenesulfonic acid) slightly accelerates $\mathrm{MeOH}$ conversion, but does not increase the final triptyl yield.

- Phosphorus additives also cause a substantial increase in the yield of methyl iodide (up to $10 \%$ of the original methanol feed); consistent with this observation, powder-pattern XRD of the solid recovered after reaction and evaporation shows that some of the zinc iodide has been converted to zinc phosphate. Analysis for content by class of hydrocarbon was carried out with a standard "PIANO" analytical routine. See the Supplementary Information for details.

II The combination of $\mathrm{H}_{3} \mathrm{PO}_{2}-\mathrm{I}_{2}$ reduces aryl olefins, but the reducing agent is thought to be $\mathrm{HI}$, with $\mathrm{H}_{3} \mathrm{PO}_{2}$ serving only to reduce $\mathrm{I}_{2}$ (see the Supplementary Information for discussion). ${ }^{7}$ Other $\mathrm{P}-\mathrm{H}$ bonded species do not behave similarly: $\mathrm{PH}_{3}$ (generated in situ by adding solid zinc phosphide) inhibits formation of any hydrocarbons, presumably by neutralizing the 
acidity required for the carbocationic mechanism and/or by consuming methylating species $\left({ }^{31} \mathrm{P}\right.$ NMR shows that $\mathrm{PMe}_{4}{ }^{+}$is formed). Phosphine derivatives such as $\mathrm{PPh}_{3}$ behave similarly.

1 G. A. Olah, Angew. Chem., Int. Ed., 2005, 44, 2636-2639.

2 (a) J. F. Haw, W. Song, D. M. Marcus and J. B. Nicholas, Acc. Chem. Res., 2003, 36, 317-326; (b) U. Olsbye, M. Bjørgen, S. Svelle, K.-P. Lillerud and S. Kolboe, Catal. Today, 2005, 106, $108-111$.

3 L. Kim, M. M. Wald and S. G. Brandenburger, J. Org. Chem., 1978, 43, 3432-3433.
4 J. E. Bercaw, P. Diaconescu, R. H. Grubbs, R. D. Kay, S. Kitching, J. A. Labinger, X. Li, P. Mehrkhodavandi, G. E. Morris, G. J. Sunley and P. Vagner, J. Org. Chem., 2006, 71, 8907-8917.

5 D. E. C. Corbridge, Phosphorus: An Outline of its Chemistry, Biochemistry and Uses, Elsevier, Amsterdam, 5th edn, 1995, pp. 246-251.

6 R. S. Edmundson, in The Chemistry of Organophosphorus Compounds, ed. F. R. Hartley, John Wiley \& Sons, Chichester, 1990, vol. 3, ch. 2, pp. $80-81$.

7 A. J. Fry, M. Allukian and A. D. Williams, Tetrahedron, 2002, 58, 4411-4415.

8 V. Shevchenko and R. Engel, Heteroat. Chem., 1997, 8, 501-503.

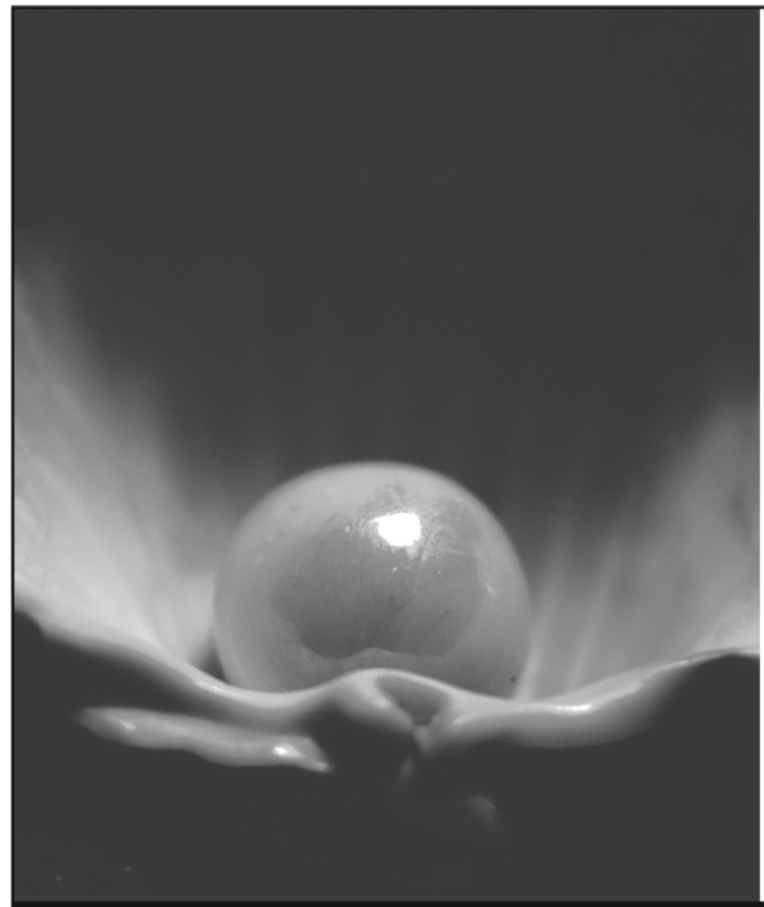

\section{Looking for that SPQCial research paper from applied and technological aspects of the chemical sciences?}

TRY this free news service:

\section{Chemical Technology}

- highlights of newsworthy and significant advances in chemical technology from across RSC journals

- free online access

- updated daily

- free access to the original research paper from every online article

- also available as a free print supplement in selected RSC journals.*

*A separately issued print subscription is also available.

Registered Charity Number: 207890 